\title{
ECLETICA
}

www.scielo.br/eq

www.ecletica.iq.unesp.br

Volume 33, número 2, 2008

\section{Morphological and thermal analyses of flexible polyurethane foams containing commercial calcium carbonate}

\author{
S. S. Sant'Annal, D. A. Souzal, C. F. Carvalho ${ }^{2}$, M. I. Yoshida ${ }^{*}$ \\ ${ }^{\prime}$ Department of Chemistry, UFMG, Av. Antônio Carlos, 6627 - Pampulha, 31270-90, Belo Horizonte - MG. \\ ${ }^{2}$ Department of Chemistry, UFOP, Campus Universitário - Morro do Cruzeiro, 35400-000 Ouro Preto - MG. \\ *mirene@ufmg.br
}

\begin{abstract}
One filler often utilized in flexible polyurethane foams is calcium carbonate $\left(\mathrm{CaCO}_{3}\right)$ because it is non-abrasiveness, non-toxicity and facilitated pigmentation. However, it is observed that the excess of commercial $\mathrm{CaCO}_{3}$ utilized in industry possibly causing permanent deformations and damaging the quality of the final product. The effect of different concentrations of commercial $\mathrm{CaCO}_{3}$, in flexible foams, was studied. Different concentrations of $\mathrm{CaCO}_{3}$ were used for the synthesis of flexible polyurethane foams, which were submitted to morphological and thermal analyses to verify the alterations provoked by the progressive introduction of this filler.
\end{abstract}

Keywords: polyurethane; flexible foam; calcium carbonate.

\section{Introduction}

The versatility of polyurethane chemistry permits the production of a great variety of materials such as flexible foams, rigid foams, films and molded devices, among others, depending on the initial ingredients used in the synthesis [1]. Flexible polyurethane foams are one of the most important classes of cellular plastic and can be applied in the fabrication of a wide range of materials for different uses such as foam mattresses, pillows, furniture, etc. [2].

When adding a filler to a polymer to form a conjugated biphasic material, the properties of the final material will be intermediate between those of the two components. The tension applied to the polymeric matrix will be transferred in part to the disperse phase, the filler, since it presents properties superior to the pure polymer [3]. Efficient reinforcement is achieved by interactions of the constituents of the biphasic material
[4-5] via mechanisms of adhesion, which could be: adsorption, chemical bonding and mechanical adhesion. Chemical bonding is the most efficient form of adhesion and occurs with the application of coupling agents on the surface of the filler, which serves as a bridge between the polymer and the reinforcement. In mechanical adhesion, the polymer fills in the grooves of the filler; this adhesion tends to be low unless there is a large number of recesses on the surface of the filler [6].

Several types of materials exist that can be used as filler. Among the inorganic materials utilized as filler, notable ones include: calcium carbonate, aluminum hydroxide, silica, titanium dioxide and talc [6]. Some of the organic materials more commonly used are carbon black [7] and natural fibers [8-9].

In flexible polyurethane foams, the fillers promote an increase in density and resistance to compression. However, they reduce the resiliency and contribute to the increase in permanent defor- 
mation. In addition, properties such as tear strength, for example, are significantly affected by the introduction of filler [10]. Accordingly, it is necessary to know the end-use of the material in order to use the correct concentration in the polymer matrix, obtaining a product of reliable quality. In spite of the polyurethane industry widely using calcium carbonate as a filler, generally the quantity used is defined randomly. In the businesses visited in the region of Belo Horizonte in Minas Gerais State - Brazil, no data was available on the influence of this filler on the foam, nor was there any methodology to define the ideal quantity of calcium carbonate that should be added without causing damage to the mechanical properties of the final product.

Thus the proposal of the present work was to analyze the morphological, mechanical and thermal behavior when various concentrations of commercial calcium carbonate were introduced into the polymer matrix using scanning electron microscopy (SEM), energy dispersive X-ray spectroscopy (EDS) microanalysis and thermal analysis.

\section{Experimental}

\section{Preparation of flexible foams}

For the fabrication of the flexible foams, the following components were used: polyether polyol Voranol 4730N (100.00 pph = parts per hundred parts of polyol) and TDI Voranate T-80 (50.00 pph) purchased from Dow Chemical; the silicone surfactant PDMS/POE (0.60 pph) from General Electric; amine Aricat AA 805 purchased from Arinos (0.16 pph) and stannous dioctoate II (Liocat 29, Miracema-Nuodex, $0.30 \mathrm{pph}$ ) were used as catalysts in the polymerization and expansion reactions [11-12]; distilled water (3.00 pph); and commercial calcium carbonate (1, 9, 15,21 and $30 \mathrm{pph}$ ) obtained from the mattress manufacturing industries in the region of Belo Horizonte. The stoichiometry of the formulation used in industry was adjusted for the lab-scale fabrication of foams. The isocyanate index used was 132. A Fisatom model 710 shaft stirring device (power: $25 \mathrm{~W}$, rotation: $25-200 \mathrm{rpm}$ ) was used for stirring.

Polyol and the filler were placed in a disposable plastic receptacle, and the mixture was stirred until complete homogenization. Next, the amine, surfactant and water were added. The mixture was submitted to mechanical stirring for 60 seconds. Shortly after the catalyst was added and the mixture was stirred again for 30 seconds. After introducing the isocyanate, the mixture was submitted to 6 seconds of stirring and then poured into a cubical cardboard box $(7 \mathrm{~cm} \times 7 \mathrm{~cm} \times 7 \mathrm{~cm})$. The foams were left to cure for seven days.

\section{Flexible foams analyses}

For the instrumental analyses, the following instruments were used: SEM - Jeol JSM-840; microanalysis (EDS) - Jeol-8900 electron probe microanalyzer; thermogravimetric analysis (TG) - Netzsch STA 409EP.

SEM - The samples were cut into little pieces $(0.5 \mathrm{~cm} \times 0.5 \mathrm{~cm} \times 0.5 \mathrm{~cm})$ using scissors. Next they were covered with a fine layer of gold to permit observation in SEM since the samples were not conductors. The samples were analyzed under magnifications of 50, 150 and 500x.

EDS - The samples of calcium carbonate were covered with a thin layer of carbon and analyzed under with an accelerating voltage of $15 \mathrm{kV}$ and a current of $20 \mathrm{nA}$.

TG - alumina crucible; dynamic atmosphere of air; $100 \mathrm{~mL} . \mathrm{min}^{-1}$ gas flow; heating rate of $10^{\circ} \mathrm{C} \mathrm{min}-1$; heating range of $25-950^{\circ} \mathrm{C}$. The sample masses were approximately $12 \mathrm{mg}$.

\section{Results and discussion}

\section{Morphological analysis of commercial calcium} carbonate

When a filler is introduced into a polymeric material, the ideal is that it has regular granulometry and that its particles are sufficiently small to enable good distribution in the matrix [7]. Figure 1 presents the image obtained in the scanning electron microscopy (SEM) of commercial calcium carbonate at a magnification of 500x.

In the image obtained, it was observed that the calcium carbonate presented irregular, heterogeneous and coarse granulometry. The calcium carbonate, used in the present work, showed a large polydispersion in granulometric analysis with sieves of defined particle sizes. The particle 


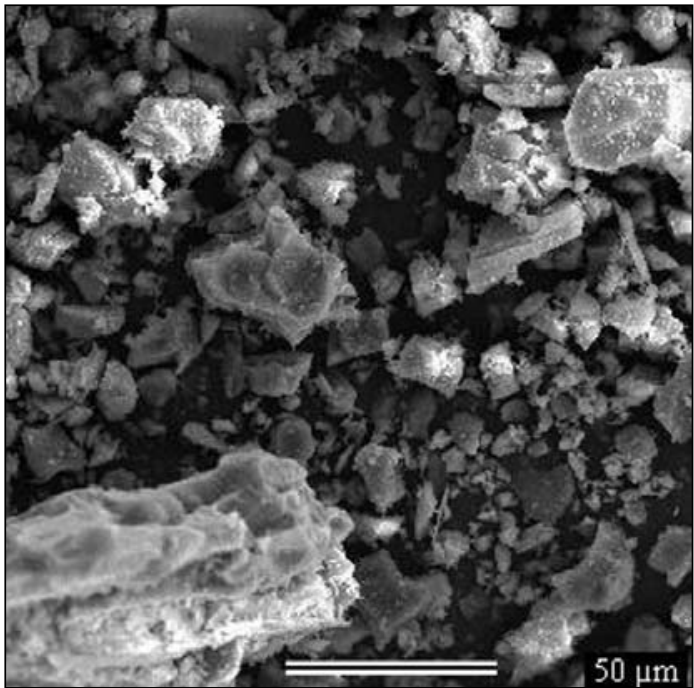

Figure 1. SEM of commercial calcium carbonate (magnification of 500x).

size varied between 200 and 250 mesh. This filler is used in the mattress industry without any pretreatment because it is a residue generated in the fabrication of lime and sold to the manufacturers at reduced prices. The calcium carbonate was also submitted to a qualitative X-ray energy dispersive spectrum (EDS, Figure 2), where it was possible to detect the various elements of its constitution. It is worth noting that to improve the foam quality, granulometry aside, the ideal is to utilize a chemically pure material that does not contain substances that could react with the matrix, leading to the degradation of the material.

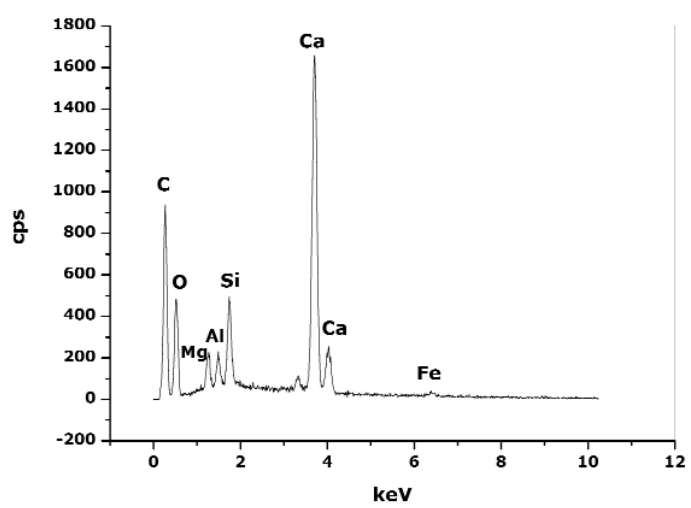

Figure 2. Microanalysis of commercial calcium carbonate.
Morphological analysis of flexible foams

Figure 3 presents the image (SEM) of the flexible foams containing calcium carbonate and its transversal section.

It is observed that the calcium carbonate added is agglomerated in some points in the polymer matrix and not evenly distributed homogeneously, as is required to promote an efficient reinforcement $[5,13]$. This result was expected since the filler utilized presented polydispersion in granulometry. A low interaction of the filler used and
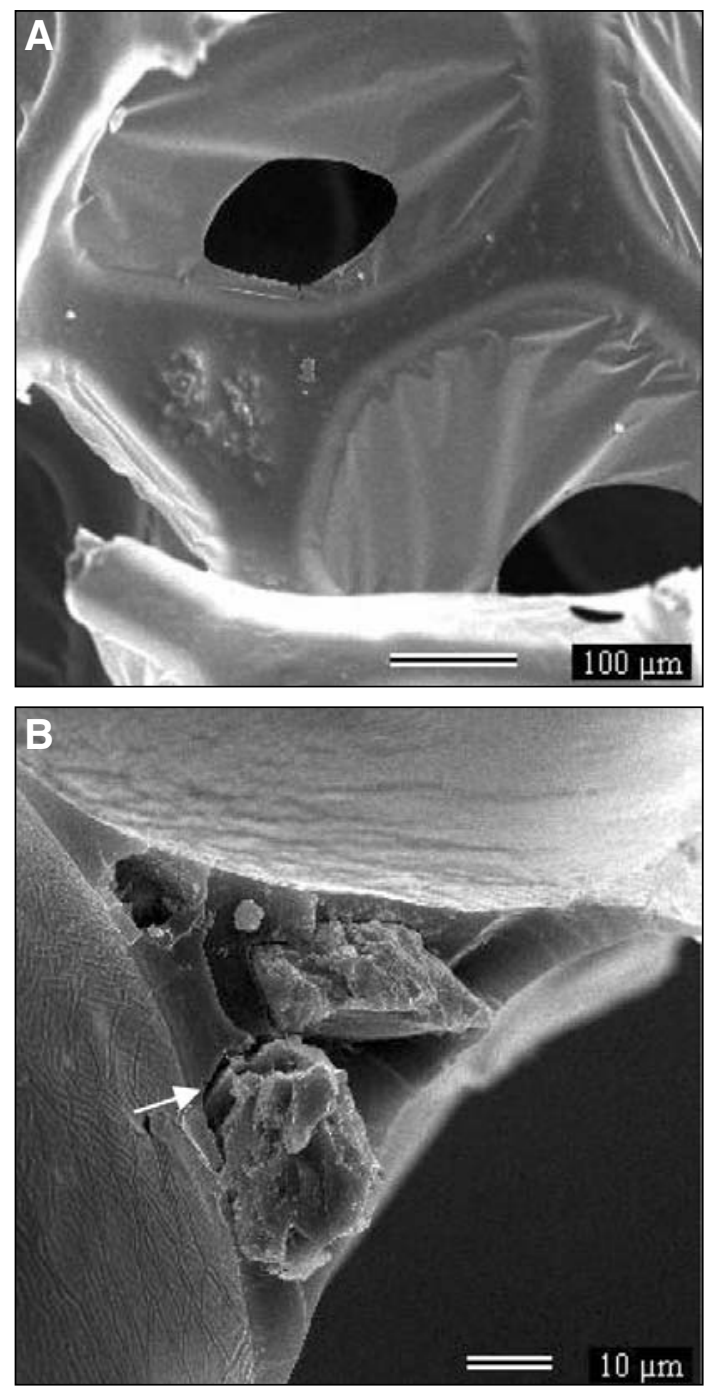

Figure 3. (a) SEM of flexible foam filled with calcium carbonate (magnification of 150 and 500x); (b) SEM of a transversal section of foam with carbonate (magnification of 1000x). 


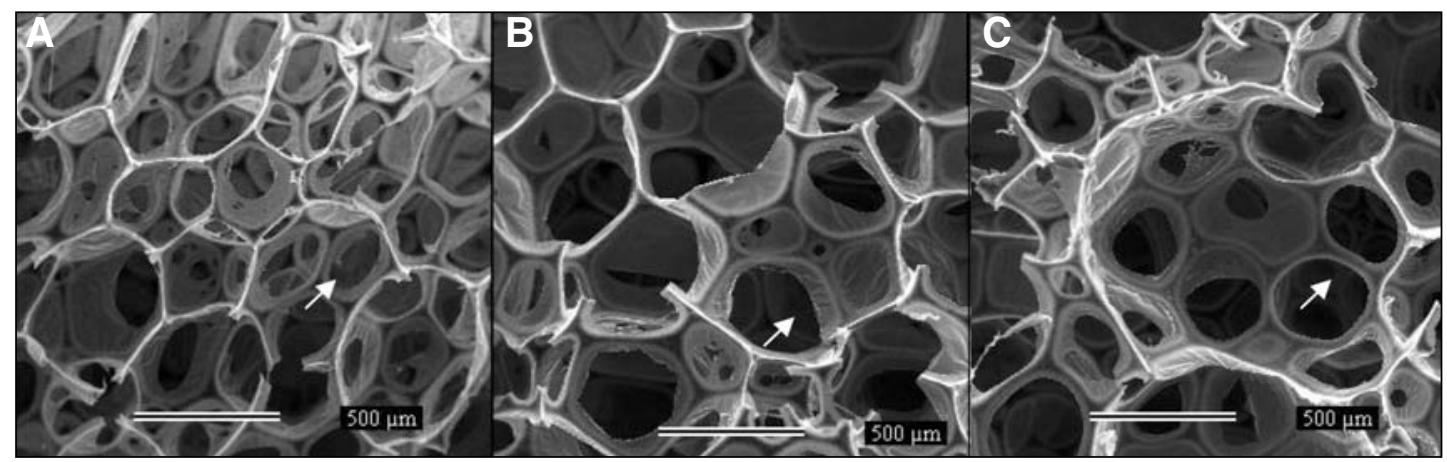

Figure 4. SEM of foam filled with carbonate at concentrations of 9, 15 and 21\% (magnification of 50x).

the polymeric matrix was further verified by microscopy, which probably contributed to the deformations observed further (Figure 4). The use of excessive quantities of filler causes enrichment, it also is responsible for damage to the matrix [14], causing the foam to lose its characteristic polyhedral morphology. The arrows show the worsening morphology as higher concentrations are added.

\section{Thermal analysis}

According to the TG curves, the polyurethane presents typical decomposition in two stages between 200 and $600^{\circ} \mathrm{C}$, generating a final residue of $1.73 \%$. The commercial calcium carbonate decomposes between 600 and $800^{\circ} \mathrm{C}$, losing $\mathrm{CO}_{2}$ and generating $\mathrm{CaO}$ with a final residue of $\sim 62.68 \%$. This high value of the residue means that the commercial calcium carbonate, probably, contains inert compounds like $\mathrm{CaO}, \mathrm{SiO}_{2}, \mathrm{Al}_{2} \mathrm{O}_{3}$, etc, compatible with the EDS analysis.

The flexible foams containing commercial calcium carbonate as a filler were also submitted to thermal analysis. Figure 5 presents the TG curves of the foams with carbonate in varying concentrations and also the TG curve of the foam without calcium carbonate.

By means of the residues obtained in the TG curves it was verified that the filler is not homogenously distributed throughout the foam since the residue percentage obtained did not correspond to the concentration of carbonate added in the sample preparation. This observation agrees with the verifications done in the morphological analysis of foams with calcium carbonate. Nevertheless a shift in decomposition temperature of the flexible foams to lower values was seen

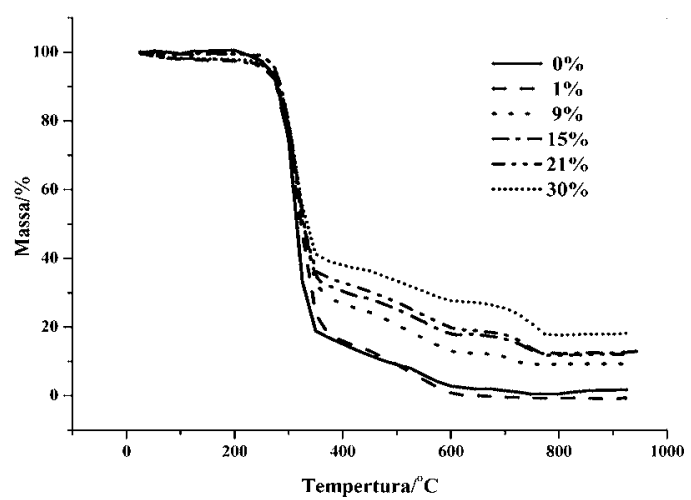

Figure 5. TG curves of flexible foams with calcium carbonate.

with an increase in calcium carbonate concentration. The foams with carbonate present three stages of decomposition, two of which are attributed to the loss of organic material and the third step is attributed to the decomposition of calcium carbonate. Figures $6 \mathrm{a}, \mathrm{b}$ and $\mathrm{c}$ display a linear dependency of the quantity of mass lost in the $1^{\text {st }}$, $2^{\text {nd }}$ and $3^{\text {rd }}$ stages of decomposition of the composites on the concentration of filler $\left(\mathrm{CaCO}_{3}\right)$.

The quantities of mass lost in the $1^{\text {st }}$ and $2^{\text {nd }}$ stages diminished with an increase in the concentration of $\mathrm{CaCO}_{3}$. As the concentration of filler did not greatly influence the decomposition of polyurethane, a directly proportional relation between the mass lost and the concentration of filler was expected. The analysis of pure polyurethane showed that $97.8 \%$ of its mass was lost in the first two stages of decomposition (Table 1).

Using an approximation of the rule of mixing and substituting the volumetric fraction for the mass fraction $[5,15-16]$ yields: 

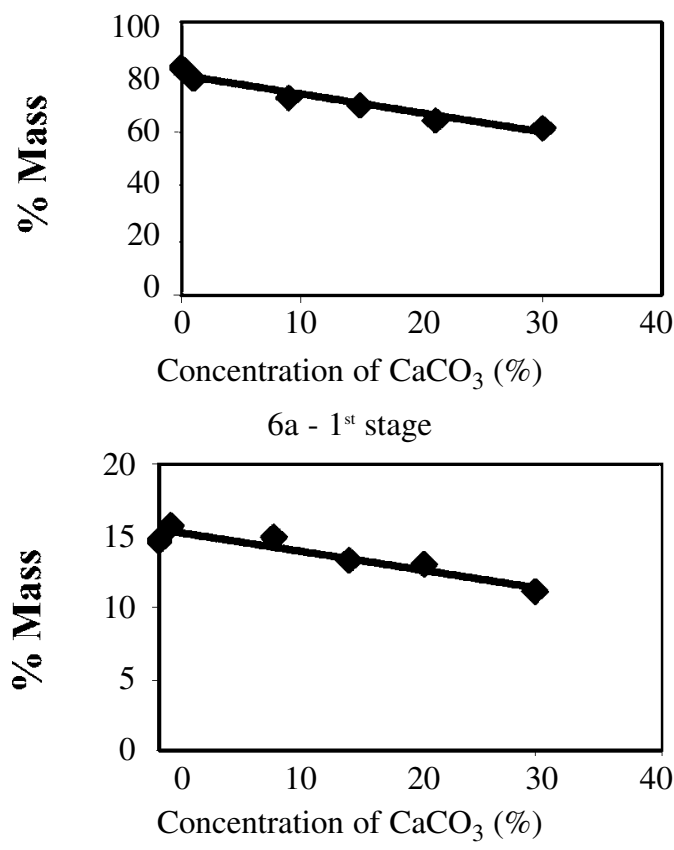

$6 b-2^{\text {st }}$ stage

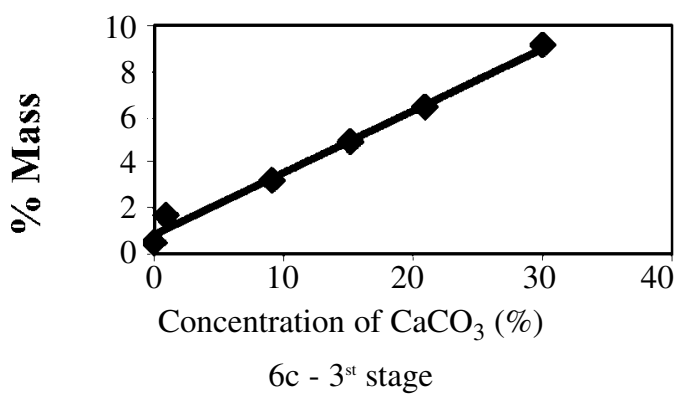

Figure 6. Loss in mass of pure polyurethane and the foams as a function of concentration of calcium carbonate $(0,1,9,15,21$ and $30 \%)$.

$$
\mathrm{CP}=\mathrm{MP} \times \mathrm{MMF}+\mathrm{RP} \times \mathrm{RMF}
$$

where:

$\mathrm{CP}$ is the property of the composite;

MP is the property of the matrix;

MMF is the mass fraction of the matrix in the composite;

$\mathrm{RP}$ is the property of reinforcement; and

RMF is the mass fraction of the reinforcement in the composite.

It is emphasized that the mass fraction was utilized preferentially because the mass losses and release of heat are more directly related to the quantities of mass utilized in the analyses than their respective volumes. Since there was no mass loss of the filler because these stages occurred at temperatures below its decomposition temperature, one can consider this loss to be zero, and using equation (1) yields: $\mathrm{CP}_{1 \%}=97.84 \times 0.99=96.86 \%$ for foam with $1 \%$ filler. Substituting the other concentrations, one obtains the mass losses in these two stages for the foams with different concentrations of commercial calcium carbonate (Table 1).

Table 1. \% Mass loss as a function of the amount of $\mathrm{CaCO}_{3}$ for the $1^{\text {st }}$ and $2^{\text {nd }}$ stages

\begin{tabular}{ccc}
$\% \mathrm{CaCO}_{3}$ & $\begin{array}{c}\text { ‡Calculated} \\
\text { mass loss }(\%)\end{array}$ & $\begin{array}{c}\text { Observed } \\
\text { mass loss }(\%)\end{array}$ \\
\hline 0 & 97.83 & 97.84 \\
1 & 96.86 & 95.29 \\
9 & 89.03 & 87.65 \\
15 & 83.16 & 82.12 \\
21 & 77.29 & 76.77 \\
30 & 68.48 & 72.39 \\
\hline
\end{tabular}

\$The quantity of calcium carbonate is expressed in g per 100 parts polyol.

The values calculated for the mass loss in the first stage of decomposition considered the hypothesis of having only weak interactions between the filler and the matrix, proportional to the mechanical adhesion. On comparing the experimental and calculated values, it can be observed that the proximity of the experimental values to the calculated ones confirms the initial hypothesis. The decomposition of the filler was the primary event in the third stage (Figure 6c). Thus the first term of the equation was considered null. Table 2 presents the calculated and observed mass losses in the third stage for all of the flexible foams with varying concentrations of calcium carbonate.

The difference generated between the calculated and observed values in the third stage are due to the dispersion of the filler in the polymer. For performing the calculations with Equation 1, the concentrations of calcium carbonate that must be aggregated in the polymer matrix were considered. However, as observed previously in the morphological and thermogravimetric analyses, the filler did not disperse well in the matrix but formed agglomerates, which influenced the results obtained in Table 2 . 
Table 2. \% Mass loss as a function of the amount of $\mathrm{CaCO}_{3}$ for the third stage.

\begin{tabular}{ccc}
\hline $\mathrm{CaCO}_{3}$ & $\begin{array}{c}\text { † Calculated } \\
\text { mass loss }(\%)\end{array}$ & $\begin{array}{c}\text { Observed } \\
\text { mass loss }(\%)\end{array}$ \\
\hline 0 & 0 & 0.43 \\
1 & 0.37 & 1.68 \\
9 & 3.36 & 3.25 \\
15 & 5.60 & 4.94 \\
21 & 7.84 & 6.38 \\
30 & 11.20 & 9.12 \\
\hline
\end{tabular}

\section{Conclusions}

The calcium carbonate did not disperse well in the matrix since it has variation in particle size and presents interactions that tend to form agglomerates, making it so that there is not a distribution of force between the carbonate and the matrix during the utilization of the flexible foam.
Although the flexible polyurethane foam factories use calcium carbonate as a filler, the introduction of high quantities of this compound corroborates with the increase in hysteresis values, leading to a loss in quality. Nevertheless, an increase in the dimensional stability was observed with an increase in calcium carbonate concentration.

The thermal stability of flexible polyurethane foams is altered with an increase in calcium carbonate concentration; this fact is related to the reduction of polyurethane in the flexible foam.

\section{Acknowledgements}

The authors thank to $\mathrm{CNPq}$ for financial support.

Received 12 May 2008

Accepted 04 June 2008

S. S. Sant'Anna, D. A. Souza, C. F. Carvalho, M. I. Yoshida. Análise térmica e morfológica de espumas flexíveis de poliuretano contendo carbonato de cálcio comercial.

Resumo: Uma das cargas mais utilizadas na fabricação de espumas flexíveis de poliuretano é o carbonato de cálcio $\left(\mathrm{CaCO}_{3}\right)$ por ser não abrasivo, não tóxico e de fácil pigmentação. Contudo, é observado que o excesso de $\mathrm{CaCO}_{3}$ comercial usado nas indústrias causa deformações permanentes, o que prejudica a qualidade do produto final. No presente trabalho é proposto o estudo do efeito da concentração de $\mathrm{CaCO}_{3}$ comercial na fabricação de espumas flexíveis de poliuretano. Foram utilizadas diferentes concentrações de $\mathrm{CaCO}_{3}$ na síntese das espumas, as quais foram submetidas à análises térmica e morfológica, afim de verificar as alterações provocadas pela introdução progressiva da carga.

Palavras-chave: poliuretano; espuma flexível; carbonato de cálcio.

\section{References}

[1] C. Ligoure, M. Cloitre, C. Le Chatelier, F. Monti, L. Leibler, Polymer 46(17) (2005) 6402.

[2] G. Woods, The ICI Polyurethanes Book, Wiley, New York., $2^{\text {nd }} . e d ., 1990$.

[3] W. D. Callister, Materials Science and Engineering: An Introduction, John Wiley \& Sons, New York, $5^{\text {th }}$. ed , 2000.

[4] R. C. R. Nunes, J. L. C. Fonseca, M. R. Pereira, Polym. Test. 19(1) (2000) 93.

[5] P. Barma, M. B. Rhodes, R. Salovey, J. Appl. Phys. 49(10) (1978) 4985.

[6] M. Rabello, Aditivação de Polímeros, Artliber, São Paulo, 2000 [7] N. Rattanasom, T. Saowapark, C. Deeprasertkul, Polym. Test. 26(3) (2007) 369.

[8] C. G. Mothé, C. R. de Araujo, M. A. de Oliveira, M. I. Yoshida, J. Therm. Anal. Calorim. 67(2) (2002) 305.
[9] C. G. Mothé, C. R. de Araujo, Thermochim. Acta 357358(14) (2000) 321.

[10] W. Vilar, Química e Tecnologia de Poliuretanos, Vilar Consultoria, Rio de Janeiro, $2^{\text {nd }}$. ed., 1998.

[11] R. Neff, A. Adedeji, C. W. Macosko, A. J. Ryan, J. Polym. Sci., Part B: Polym. Phys. 36(4) (1998) 573.

[12] J. P. Armistead, G. L. Wilkes, R. B Turner, J. Appl. Polym. Sci. 35(3) (1988) 601.

[13] M. Shui, Appl. Surf. Sci. 220(1- 4) (2003) 359.

[14] R. P. Singh, M. Zhang, D. J. Chan, J. Mater. Sci. 37(4) (2002) 781.

[15] R.M.N. Arib, S. M. Sapuan, M. M. H. M. Ahmad, M.T. Paridah, H. M. D. Khairul Zaman, Materials and Design 27(5) (2006) 391.

[16] M. van der Schuur, E. van der Heide, J. Feijen, R. J. Gaymans, Polymer 45(8) (2004) 2721. 